\title{
RANCANG BANGUN SISTEM INFORMASI PENJUALAN PADA RESTORAN HANBOOK BERBASIS DESKTOP
}

\author{
Muhammad Yanuar Ramdhani ${ }^{1}$, Fitriana Destiawati², Forkas Tiroy Santos Butar-Butar ${ }^{3}$ \\ 1,2,3 Universitas Indraprasta PGRI \\ Jalan Raya Tengah No.80, Kelurahan Gedong, Pasar Rebo, Jakarta Timur \\ 1. myr2801@gmail.com, ${ }^{2}$ honeyzone86@gmail.com, ${ }^{3}$ ftsb43dharma@gmail.com
}

\begin{abstract}
ABSTRAK
Restoran hanbok adalah sebuah usaha di dalam bidang kuliner yang dimana sistem informasi penjualan yang dijalankan masih secara manual. Seperti dalam hal pendataan, pemesanan dan pembuatan laporan semuanya ditulis disebuah buku kecil dan disimpan dalam buku besar. Tujuan penelitian ini dilakukan adalah untuk merancang sebuah aplikasi yang dapat mempermudah segala sesuatu yang berhubungan dengan penjualan restoran. Metode penelitian yang digunakan adalah metode survei yang dimana termasuk kedalam metode penelitian kuantitatif yang menggunakan teknik pengumpulan data dengan melakukan wawancara dan menggunakan metode waterfall sebagai langkah-langkah pengembangan sistem. Hasil dari penelitian ini adalah sebuah aplikasi sistem informasi penjualan yang sudah terkomputerisasi agar mempermudah para tenaga kerja dalam menjalankan pekerjaannya.
\end{abstract}

Kata Kunci: Sistem Informasi, Penjualan, Berbasis Desktop

\begin{abstract}
A hanbok restaurant is a business in the culinary field where the sales information system is still run manually. As in the case of data collection, ordering and making reports, everything is written in a small book and stored in a ledger. The purpose of this research is to design an application that can simplify everything related to restaurant sales. The research method used is a survey method which is included in the quantitative research method that uses data collection techniques by conducting interviews and using the waterfall method as system development steps. The result of this research is an application of a computerized sales information system to make it easier for workers to carry out their work
\end{abstract}

Key Word: Information Systems, Sale, Desktop Base

\section{PENDAHULUAN}

Kegiatan jual beli pada saat ini mengalami banyak kemajuan yang signifikan berbanding lurus dengan perkembangan teknologi. Seiring berkembangnya penjualan di indonesia dalam hal jual beli mengalami peningkatan tiap tahunnya dan dapat dilihat dari bertambahnya jual beli, dengan jumlah penduduk di indonesia yang terus bertambah merupakan potensi yang sangat besar untuk membuka usaha jual beli. Salah satu tempat jual beli di indonesia adalah restoran. Restoran atau rumah makan adalah usaha penyediaan jasa makanan dan minuman dilengkapi dengan peralatan dan perlengkapan untuk proses pembuatan, penyimpanan dan penyajian di suatu tempat tetap yang tidak berpindah-pindah dengan tujuan memperoleh keuntungan atau laba (Muchlisin Riadi, 2017). Restoran Hanbok terletak di jl. Lapangan tembak no. B1 Cibubur Kecamatan Ciracas Jakarta Timur. Restoran Hanbok adalah restoran berbasis franchise dengan berfokus kepada makanan yang berbasis masakan Korea dan BBQ. Tempat yang dipilih oleh penulis sudah memenuhi kriteria penulis yaitu sistem penjualan makanan pada restoran ini masih menggunakan sistem manual. Sistem pemesanan dilakukan jika pembeli sudah menentukan pemesanan mekanan dan memanggil pelayan untuk mencatat order.

Bagaimana jika dibuat suatu sistem baru untuk solusi permasalahan yang ada pada restoran tersebut yaitu, penulis akan membuat sistem penjualan yang terkomputerisasi dan terhubung ke database agar dapat memudahkan para pekerja dalam menjalankan tugasnya.

Penelitian yang berjudul "Perancangan Aplikasi Pemesanan Makanan dan Minuman Berbasis ERP (Open ERP) Di Cafe Cozy", (Nugroho, 2021) Universitas Indraprasta PGRI, dengan tujuan diterapkannya sistem tersbut dapat meningkatkan kinerja cafe terutama dalam pencatatan dan penyimpanan 
data pada cafe, mendapatkan informasi secara real time dan akurat tentang info produk, pemesanan, penjualan, dan accounting serta mempermudah dalam pembuatan laporan/dokumen,

Penelitian yang berjudul "Perancangan Aplikasi Pemesanan Makanan dan Minuman Pada Rumah Makan Cepat Saji D'BESTO”, (Setiawan et al., 2020) Universitas Indraprasta PGRI, dengan tujuan dapat mempermudah pekerjaan dalam pencatatan dan pemesanan data ketersediaan menu data makanan, minuman dan data penjualan agar pemesanan lebih mudah.

\section{METODE PENELITIAN}

Metode penelitian adalah cara melakukan sesuatu dengan menggunakan pikiran secara seksama untuk mencapai suatu tujuan (Priyono, 2016). Penelitian kuantitatif berkaitan erat dengan teknik-teknik survai sosial termasuk wawancara terstruktur dan kuesioner yang tersusun, eksperimen, observasi terstruktur, analisis isi, analisis statistik formal dan masih banyak lagi (Nizar, 2015). Secara umum metode penelitian kuantitatif terdiri dari atas 2 metode yaitu metode survey dan metode eksperimen. Dalam implementasinya ada metode yang digunakan, yaitu metode survey dimana metode survey adalah metode penelitian kuantitatif yang digunakan untuk mendapatkan data yang terjadi pada masa lampau atau saat ini, teknik pengumpulan data dapat dilakukan dengan wawancara atau kuisioner. Melalui metode penelitian tersebut penulis berharap dapat mengumpukan data secara tepat dan akurat (ranahresearch.com, 2018). Metode pengembangan sistem yang digunakan adalah metode waterfall dengan tahapan sebagai berikut :

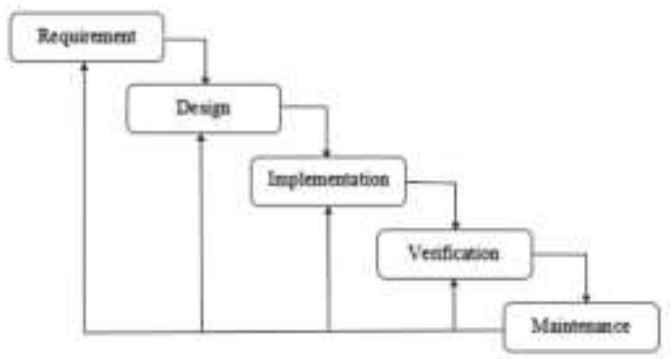

Gambar 1. Langkah-Langkah Pengembangan Sistem

Sumber : (Galandi, 2016)

\section{HASIL DAN PEMBAHASAN}

Analisis Permasalahan

Dari hasil penelitian yang telah di lakukan maka penulis dapat menganalisa permasalahan yang ada pada pengelolaan pendataan pada Hanbok antara lain :

1.Pengkasiran masih menghitung manual atau masih menggunakan tulisan tangan

2.Tidak adanya suatu sistem database yang mampu mengorganisir data dengan baik.

3.Terdapat kesulitan dalam pembuatan laporan

4.Ada nya resiko hilangnya dan rusaknya dokumen.

\section{Aturan Bisnis Diusulkan}

1.Proses pendataan, dimana kepala toko menginput semua data mulai dari data karyawan, data menu, data pembelian, dan restock bahan kedalam sebuah aplikasi dan menyimpan data-data tersebut di sebuah database

2.Proses Transaksi, dimana kepala toko menginput pesanan pelanggan kedalam sebuah aplikasi lalu menghitung jumlah total semua pesanannya dan memberikan bukti pembayaran yang sah kepada pemesan.

3.Proses Laporan, dimana kepala toko mengambil semua data yang diperlukan di database lalu mencetak data tersebut menjadi sebuah laporan yang nantinya akan diserahkan kepada pemilik toko.

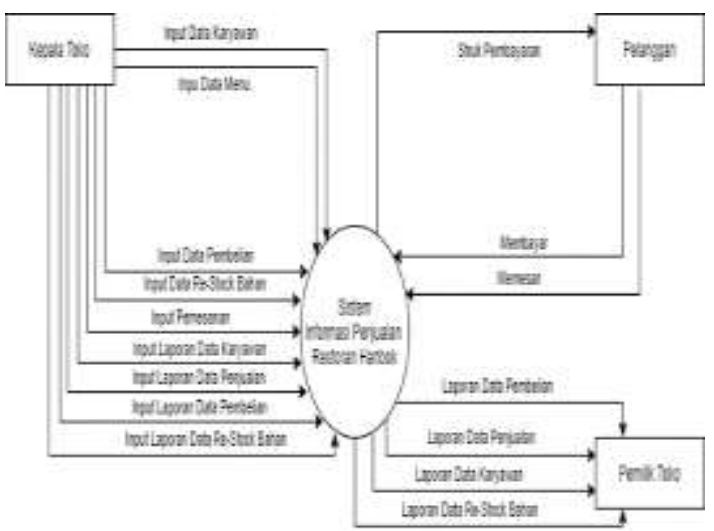

Gambar 2. Diagram Konteks

Gambar diatas adalah gambar diagram konteks yang menjelaskan sistem informasi penjualan yang diusulkan secara umum. 


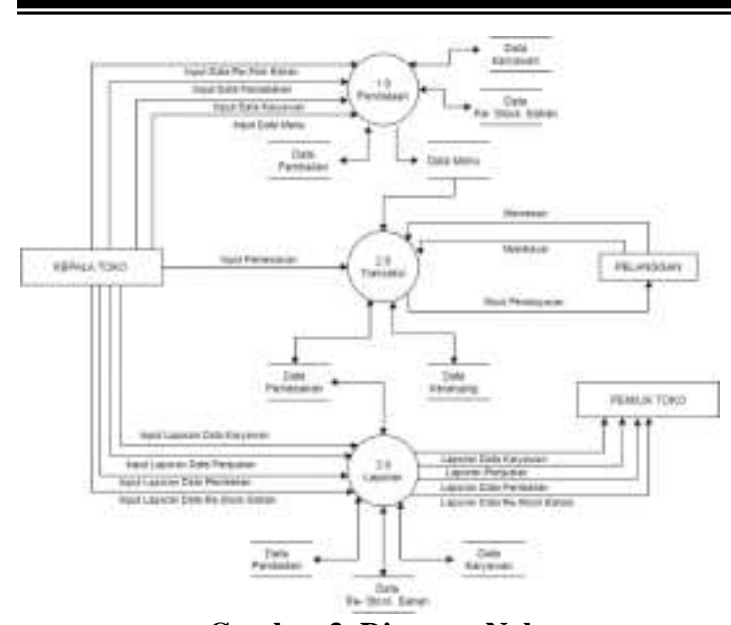

Gambar 3. Diagram Nol

Gambar diatas adalah gambar diagram nol yang menjelaskan proses apa saja yang dalam sistem yang diusulkan. Pada diagram terdiri dari berbagai proses, mulai dari proses pendataan dimana kepala toko memasukkan berbagai macam data dan menyimpannya disebuah database. Kemudian ada proses transaksi dimana pelanggan memesan dan kepala toko menginput pemesanan tersebut, setelah pemesanan selesai pelanggan membayar lalu kepala toko memberikan bukti pembayaran yang sah kepada pelanggan. Proses yang terakhir yaitu laporan dimana kepala toko menginput laporan lalu mencetaknya dan memberikan laporan tersebut kepada pemilik toko sebagai laporan bulanan.

\section{Normalisasi}

Normalisasi merupakan proses pengelompokan elemen data menjadi tabeltabel yang menunjukan entitas dan relasinya (Sutabri, 2012).

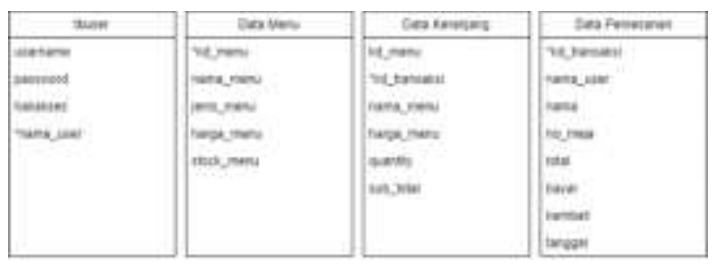

Gambar 4. Normalisasi 1NF

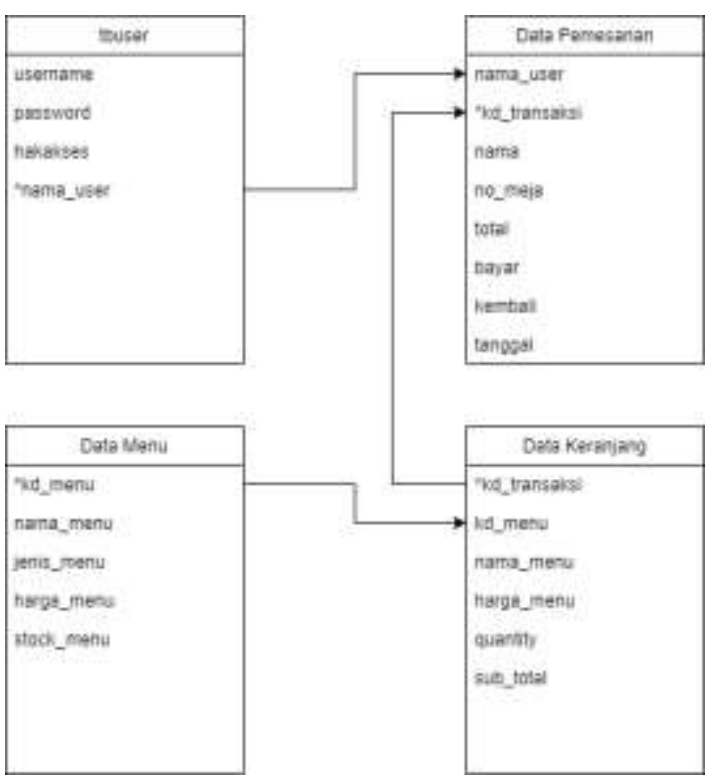

Gambar 5. Normalisasi 2NF

\section{ERD (Entity Relationship Diagram)}

ERD menjadi salah satu pemodelan data konseptual yang paling sering digunakan dalam proses pengembangan basis data bertipe relasional (Lubis, 2016).

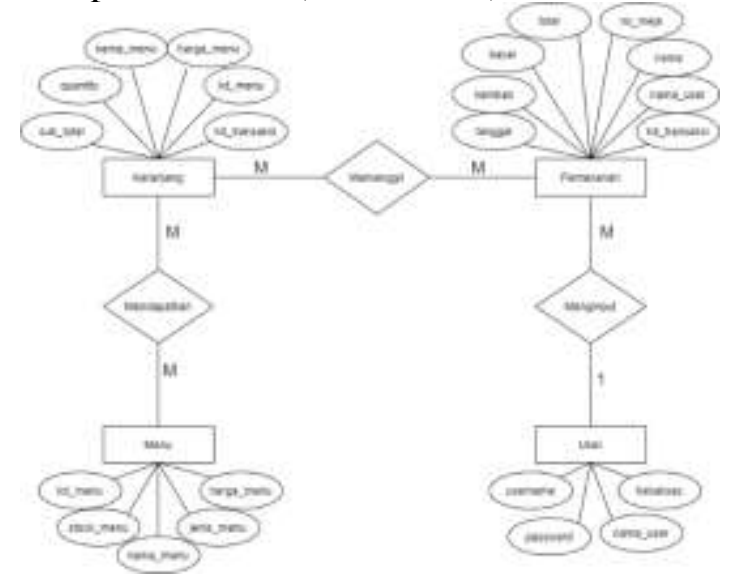

Gambar 5. Normalisasi 2NF

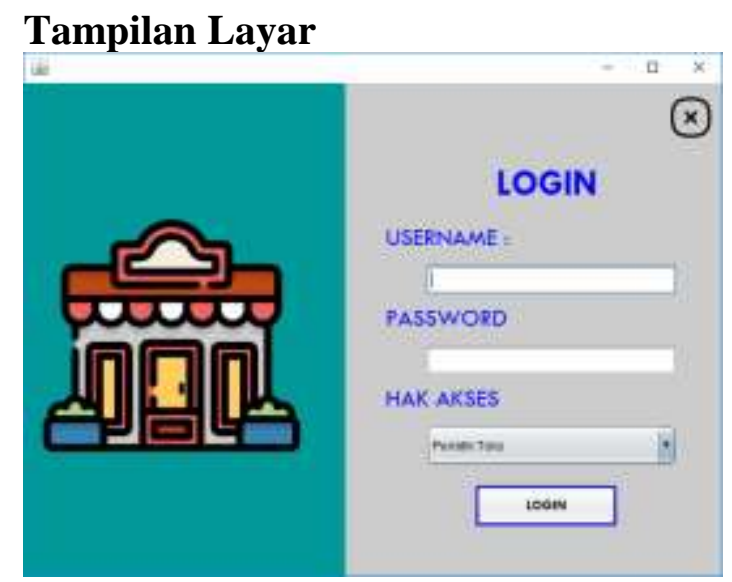

Gambar 6. Tampilan Layar Menu Login 
Tampilan layar menu login diatas adalah menu yang akan pertama kali keluar ketika program dibuka. Pada menu tersebut pengguna diharuskan untuk mengisi username, password, dan hak akses agar dapat menjalankan program.

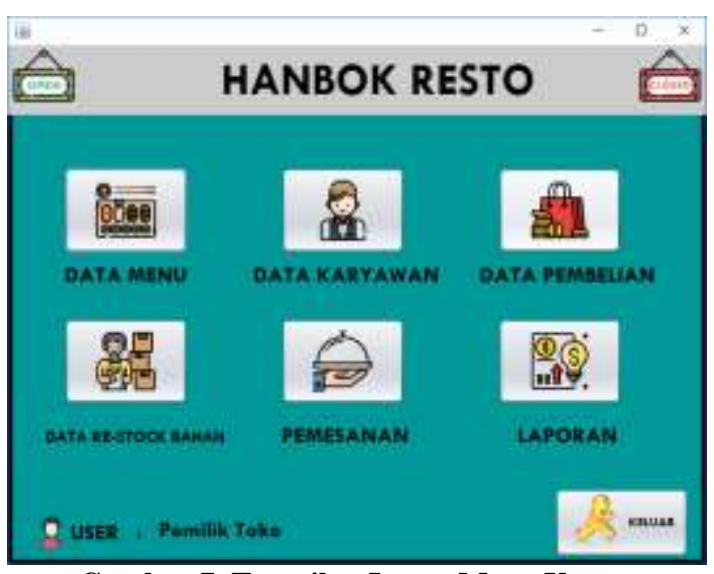

Gambar 7. Tampilan Layar Menu Utama

Tampilan layar menu utama diatas adalah menu yang akan keluar setelah pengguna berhasil melakukan login. Terdapat nama restoran, nama user dan berbagai tombol seperti tombol data menu, data karyawan, data pembelian, data re-stok bahan, pemesanan, laporan dan keluar. Setiap tombol akan memiliki aksi yang berbeda beda.

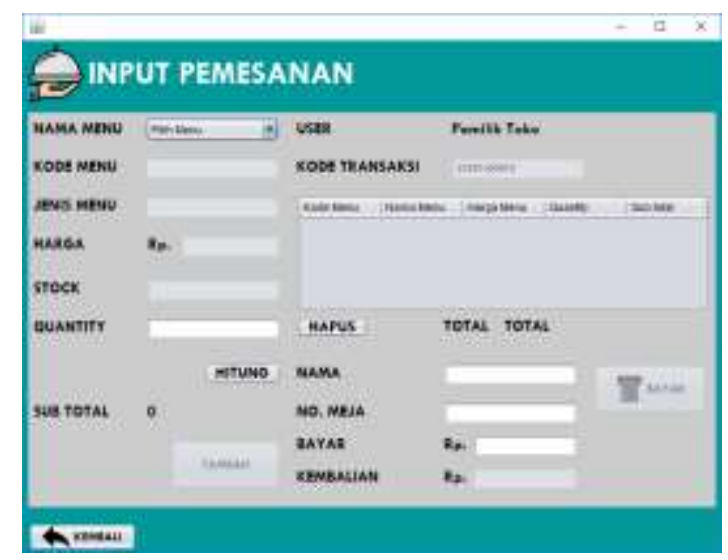

Gambar 8. Tampilan Layar Pemesanan

Tampilan layar pemesanan diatas digunakan untuk setiap adanya pelanggan yang memesan menu dan user memasukkan pesanan yang dipesan, nama pemesan, no meja, dan pembayaran. Setelah selesai pengguna akan mencetak struk pembayaran yang akan diberikan kepada pemesan dan pemesanan segera di proses.
Tabel 1. Pengujian Aplikasi

\begin{tabular}{|c|c|c|c|}
\hline No & Masukan & $\begin{array}{c}\text { Keluaran } \\
\text { yang } \\
\text { Diharapkan }\end{array}$ & Kesimpulan \\
\hline 1. & $\begin{array}{l}\text { Input } \\
\text { Sembaran } \\
\text { g } \\
\text { username, } \\
\text { password, } \\
\text { dan hak } \\
\text { akses }\end{array}$ & $\begin{array}{l}\text { Akan muncul } \\
\text { pemberitahua } \\
\mathrm{n} \\
\text { username,pass } \\
\text { word atau hak } \\
\text { askes tidak } \\
\text { sesuai }\end{array}$ & Diterima \\
\hline 2. & $\begin{array}{l}\text { Salah satu } \\
\text { username, } \\
\text { password, } \\
\text { atau hak } \\
\text { akses } \\
\text { tidak diisi }\end{array}$ & $\begin{array}{l}\text { Akan muncul } \\
\text { pemberitahua } \\
\mathrm{n} \text { lengkapi } \\
\text { inputan login }\end{array}$ & Diterima \\
\hline 3. & $\begin{array}{l}\text { Input } \\
\text { username, } \\
\text { password, } \\
\text { dan hak } \\
\text { akses } \\
\text { dengan } \\
\text { benar }\end{array}$ & $\begin{array}{l}\text { Tampilan } \\
\text { Menu Utama }\end{array}$ & Diterima \\
\hline 4. & $\begin{array}{l}\text { Memilih } \\
\text { Menu } \\
\text { Data } \\
\text { Menu }\end{array}$ & $\begin{array}{l}\text { Akan } \\
\text { Menampilkan } \\
\text { form Data } \\
\text { Menu Dimana } \\
\text { dapat } \\
\text { menmbahkan, } \\
\text { menhapus } \\
\text { ataupun } \\
\text { mengubah } \\
\text { data yang ada }\end{array}$ & Diterima \\
\hline 5. & $\begin{array}{l}\text { Memilih } \\
\text { Menu } \\
\text { Data } \\
\text { Karyawan }\end{array}$ & $\begin{array}{l}\text { Akan } \\
\text { Menampilkan } \\
\text { form Data } \\
\text { Karyawan } \\
\text { Dimana dapat } \\
\text { menmbahkan, } \\
\text { menhapus } \\
\text { ataupun } \\
\text { mengubah } \\
\text { data yang ada }\end{array}$ & Diterima \\
\hline 6. & $\begin{array}{l}\text { Memilih } \\
\text { Menu } \\
\text { Data } \\
\text { Pembelian }\end{array}$ & $\begin{array}{l}\text { Menampilkan } \\
\text { form Data } \\
\text { Pembelian } \\
\text { Dimana dapat } \\
\text { menambahkan } \\
\text { data } \\
\text { pembelian }\end{array}$ & Diterima \\
\hline 7. & $\begin{array}{l}\text { Memilih } \\
\text { Menu } \\
\text { Data Re- } \\
\text { Stock } \\
\text { Bahan }\end{array}$ & $\begin{array}{l}\text { Menampilkan } \\
\text { form Data Re- } \\
\text { Stock Bahan } \\
\text { Dimana dapat } \\
\text { menmbahkan } \\
\text { data re-stock } \\
\text { bahan }\end{array}$ & Diterima \\
\hline 8. & $\begin{array}{l}\text { Mrmilih } \\
\text { Menu } \\
\text { Pemesana } \\
\text { n }\end{array}$ & $\begin{array}{l}\text { Menampilkan } \\
\text { form } \\
\text { Pemesanan } \\
\text { dimana dapat } \\
\text { memasukkan } \\
\text { data } \\
\text { pemesanan } \\
\text { serta } \\
\text { mencetak }\end{array}$ & Diterima \\
\hline
\end{tabular}




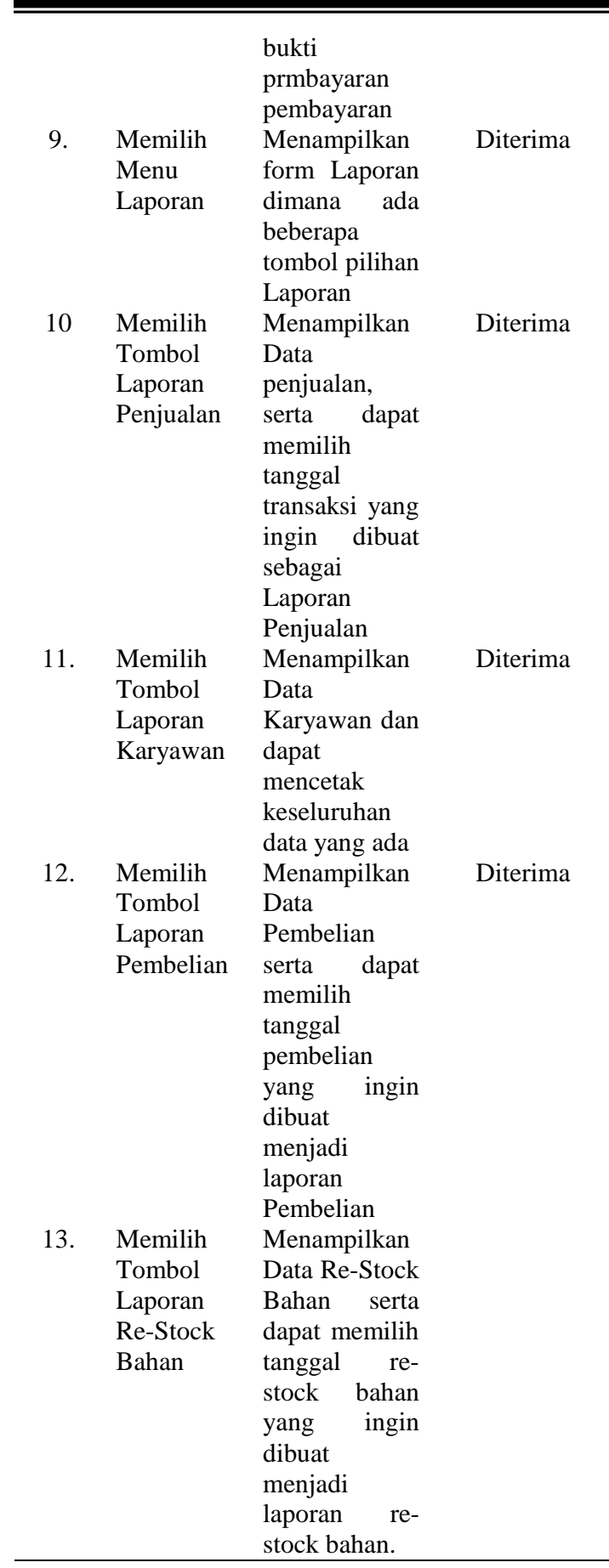

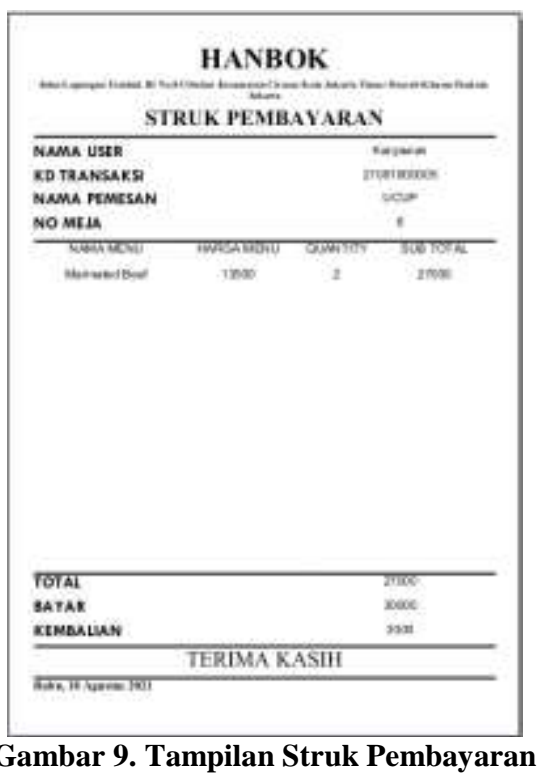

Tampilan diatas adalah contoh gambar struk pembayaran yang akan diterima oleh pelanggan.

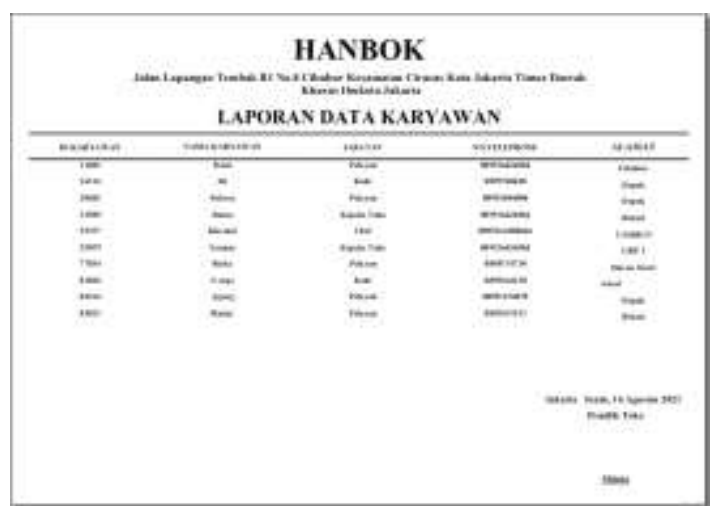

Gambar 10. Tampilan Laporan Data Karyawan

Tampilan diatas adalah contoh gambar laporan data karyawan yang bekerja pada restoran tersebut dan diberikan kepada pemilik toko.

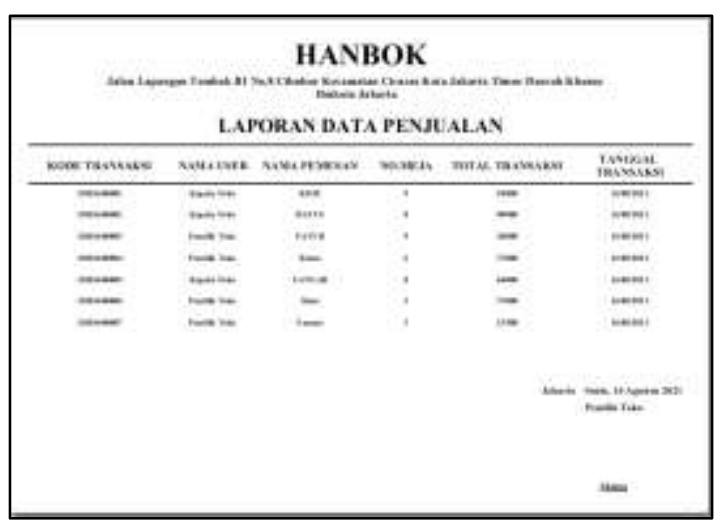

Gambar 11. Tampilan Laporan Data Penjualan 
Tampilan diatas adalah contoh gambar laporan data penjualan setiap bulannya yang diberikan kepada pemilik toko secara ruitn sebulan sekali.

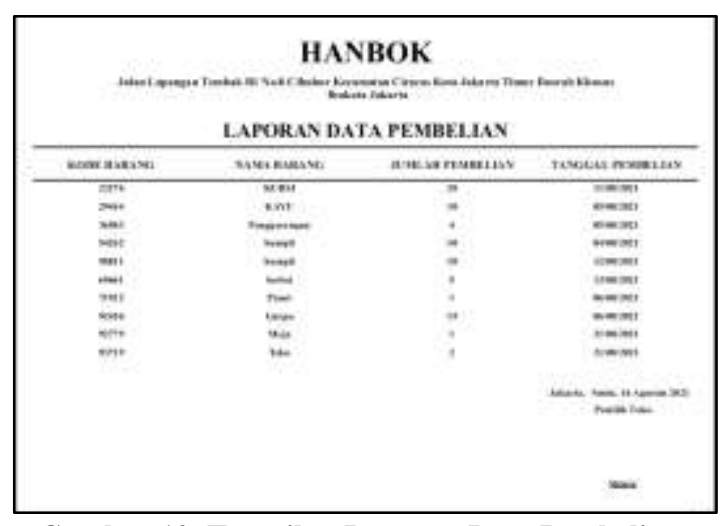

Gambar 12. Tampilan Laporan Data Pembelian

Tampilan diatas adalah contoh gambar laporan data pembelian perlengkapan untuk kepentingan restoran yang diberikan kepada pemilik toko.

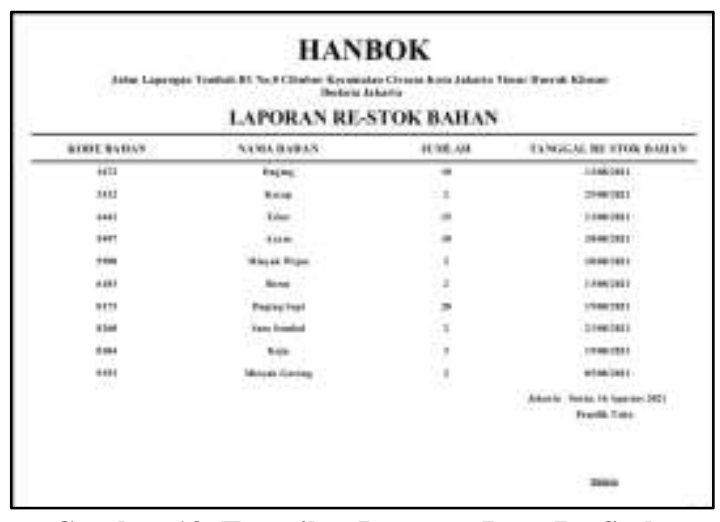

Gambar 13. Tampilan Laporan Data Re-Stok Bahan

Tampilan diatas adalah contoh gambar laporan data re-stok bahan yang masuk untuk membuat menu makanan yang ada dan diberikan kepada pemilik toko.

\section{SIMPULAN DAN SARAN}

Berdasarkan pembahasan diatas, dengan adanya sistem yang telah diusulkan diharpkan dapat memudahkan karyawan dalam melakukan kegiatan yang ada di Restoran HANBOOK dan membuat kinerja menjadi efektif dan mengefisienkan waktu bekerja, maka dari itu penulis dapat mengambil beberapa kesimpulan sebagai berikut :

Dengan aplikasi yang sudah terkomputerisasi ini dapat membantu setiap karyawan dalam menangani setiap proses transaksi yang ada secara cepat dan tepat. Pada sistem ini, dapat membantu kepala toko dalam melakukan pendataan karyawan, pendataan menu, pendataan pembelian, dan pendataan re-stok bahan dan menyimpannya di sebuah database, berbeda dengan sebelumnya yang masih menggunakan pencatatan secara manual dan menggunakan buku sebagai media penyimpanannya dimana tidak terjamin keamanan data tersebut. Pada sistem ini, dapat membantu kepala toko dalam proses pembuatan laporan menjadi lebih cepat, tepat, dan akurat.

Berdasarkan kesimpulan yang sudah dibuat, penulis menyadari masih adanya kekurangan pada program yang dibuat, berikut adalah saran yang dapat diberikan oleh penulis adalah sebelum menggunakan aplikasi sistem informasi penjualan digunakan, alangkah baiknya setiap karyawan yang bekerja pada restoran Hanbok diberikan penjelasan dan tata cara dalam menggunakan aplikasi tersebut agar tidak terjadi kekeliruan. Diharapkan adanya backup data secara berkala untuk mencegah kehilangan data yang ada. Peneliti berharap adanya pengembangan sistem yang lebih luas untuk mempermudah sistem penjualan yang ada pada restoran HANBOOK.

\section{DAFTAR PUSTAKA}

Galandi, F. (2016). Metode Waterfall: Definisi, Tahapan, Kelebihan dan Kekurangan. Retrieved Desember, 28, 2019.

Lubis, A. (2016). Yogyakarta: CV Budi Utama Basis Data Dasar Untuk Mahasiswa Ilmu Komputer.

Muchlisin Riadi. (2017). Pengertian, Jenis dan Sistem Pelayanan Restoran. Www.Kajianpustaka.Com. https://www.kajianpustaka.com/2017/1 1/pengertian-jenis-dan-sistempelayanan-restoran.html

Nizar, A. (2015). Metode Penelitian Pendidikan Pendekatan Kuantitatif, Kualitatif, PTK, dan Penelitian Pengembangan. cet. 2. Bandung: Citapustaka Media.

Nugroho, A. (2021). Perancangan Aplikasi Pemesanan Makanan dan Minuman Berbasis ERP (Open ERP) di Cafe Cozy. Jurnal Riset Dan Aplikasi Mahasiswa Informatika (JRAMI), 2(02), 356-363. 
https://doi.org/10.30998/jrami.v2i02.68 0

Priyono, M. (2016). Metode penelitian kuantitatif. Sidoarjo: Zifatma Publishing.

ranahresearch.com. (2018). Pengertian Metode Penelitian dan Jenis-jenis Metode Penelitian.

Https://Ranahresearch.Com/.

https://ranahresearch.com/metodepenelitian-dan-jenis-metode-penelitian/ Setiawan, H., Rahayu, W., \& Kurniawan, I. (2020). Perancangan Aplikasi Pemesanan Makanan dan Minuman pada Rumah Makan Cepat Saji D'besto. Jurnal Riset Dan Aplikasi Mahasiswa Informatika (JRAMI), 1(03), 347-354. https://doi.org/10.30998/jrami.v1i03.35 6

Sutabri, T. (2012). Analisis sistem informasi. Penerbit Andi. 